\title{
Correction of enophthalmos and deep supratarsal sulcus by posterior subperiosteal glass bead implantation
}

\author{
GAMILO TAIARA* AND BYRON SMITH
}

From the Department of Oculo-Plastic and Reconstructive Surgery and of Ophthalmology, Manhattan Eye, Ear and Throat Hospital, New York, U.S.A.

Enophthalmos and deep supratarsal sulcus occur in a variety of conditions when there is disparity between the volume of the bony orbit and its contents, the most frequent cause being surgical anophthalmos.

Several surgical methods and materials to correct such deformities have had varying degrees of success. Data on 55 patients who underwent posterior orbital subperiosteal glass bead implantation show that this procedure has been consistently successful. This paper describes the procedure and its complications and the results in these cases.

Outward displacement of the orbital walls or communication with the neighbouring paranasal sinuses, as in fractures, produces an increase in the bony orbital volume. Anophthalmos, microphthalmos, evisceration, extruded enucleation and evisceration implants, and soft tissue atrophy all decrease the volume of the orbital contents. A combination of both mechanisms produces enophthalmos in orbital fractures. Rare conditions, such as Horner's syndrome, progressive lipodystrophy, and facial hemiatrophy, may also produce enophthalmos.

The "blow-out" type of fracture is the most common orbital fracture in this series. Tripod fractures will cause enophthalmos when the orbital floor is comminuted or displaced by rotation of the zygoma.

Enucleation results in a loss of orbital contents equalling $\mathrm{I} \cdot 5$ to $2 \cdot 5 \mathrm{cu} . \mathrm{cm}$. The volume of the eyeball is 6.5 to $7 \mathrm{cu}$. cm., that of a No. 18 ball implant is $3 \mathrm{cu} . \mathrm{cm}$., and that of the prosthesis $\mathrm{I} \cdot 5$ to $2 \mathrm{cu}$. $\mathrm{cm}$. Therefore, the total amount removed is 6.5 to 7 $\mathrm{cu} . \mathrm{cm}$. and the replacement only 4.5 to $5 \mathrm{cu} . \mathrm{cm}$., leaving a deficit of $2 \mathrm{cu} . \mathrm{cm}$.

Other main reasons why anophthalmos produces enophthalmos are gravity and the atrophy of orbital fat and muscles. The supratarsal sulcus is deformed by the pull of the fascial attachment of the superior rectus to the levator. This has been described by Sherman (1952), Stone (1965), Bartlett (1966), and Spaeth (1970).

Another cause of a deep supratarsal sulcus is the downward displacement of the prosthesis due to relaxation of the lower lid in the elderly.

A modification of the prosthesis should be tried first to correct enophthalmos and decp supratarsal sulcus. This may be effective when the defect is minor. If not, organic or alloplastic orbital implants can be used. DeVoe ( 1945 ) reported the use of dermal grafts under the skin of the upper lid. Fascia lata has been interposed between the orbicularis muscle and the septum of the upper lid or deep in the orbit (Cutler, r946). We think 
that iliac crest bone may be indicated to repair a fracture of the orbital floor in the presence of infection.

All these autogenous or homogenous implants mentioned have the disadvantage of losing volume through atrophy and reabsorption, thereby diminishing the immediate cosmetic gain.

Several alloplastic materials have been used by different methods of implantation. Silastic plates affixed to the posterior aspect of the upper eyelid septum (Vannas, I958) or implanted behind the orbicularis (Callahan, I966), acrylic plates on the floor of the orbit (Hughes, I 955), and liquid silicone rubber injected between the orbicularis muscle and the septum, or in the posterior orbit (Hill and Radford, i965) have all been tried. Liquid silicone migrates into the tissues, especially around the injection tract and even beyond it, and inflatable devices placed into the orbit may soon become inextensible because of surrounding adhesions and fibrosis.

Smith, Obear, and Leone ( 1967 ) first reported the use of Pyrex brand solid glass beads* placed under the periosteum of the posterior orbit for the correction of enophthalmos and supratarsal deformity in 25 cases of anophthalmic enophthalmos. The longest duration of follow-up reported was 3 years. All the patients were cosmetically improved $\ddagger$ and very few complications ensued. However, the authors felt that a longer follow-up 은 was needed to make a definite evaluation of the new method. A second report was made $\overrightarrow{-}$ by Smith, Leone, and Beyer (197I) on 35 cases of subperiosteal and intrascleral glass bead implants, in which the only complications mentioned were overcorrection and undercorrection.

\section{Material and methods}

This article describes 55 cases of posterior orbital subperiosteal bead implants, 34 of which have bee followed for an average period of ${ }_{1} 6.4$ months, the maximum being $6 \cdot 5$ years. Most of them were operated on within the last 5 years. The age of the patients ranged from 5 to 73 years.

The object of the operation is to bring the intraorbital tissues forward by implanting glass beads behind them into a space created between the periosteum and the orbital bones.

We prefer a general anaesthetic to gauge the necessary volume of beads more accurately. Local anaesthesia can be used, but it distorts the orbital volume and may result in an undercorrection. The beads are solid Pyrex brand glass, measuring $5 \mathrm{~mm}$. in diameter, and there are approximately eighteen per cubic centimetre by fluid displacement.

Ampicillin $500 \mathrm{mg}$. four times a day is given for 5 days, starting the day preceding surgery for prophylaxis against infection. Pre-existing superficial chronic socket infections should be treated and controlled before surgery.

OPERATIVE PROCEDURE

A horizontal incision $\mathrm{I} \cdot 5$ to $2 \mathrm{~cm}$. long is made through the skin, subcutaneous tissue, and muscle in the temporal area, starting at the lateral orbital rim (Fig. A). A vertical incision is made through the periosteum on the rim above and below the insertion of the lateral canthal raphe (Fig. B). The periosteal incision should be made approximately $\mathrm{I} \mathrm{cm}$. long to permit the introduction of a periosteal elevator and a glass bead. The periosteum is undermined posteriorly. This manoeuvre should be done carefully, maintaining contact of the elevator with the bone, and using the orbital rim as a fulcrum to avoid tearing the periosteum. The dissection should stop short of the horizontal midline 0 of the orbit to prevent injury to the supraorbital and infraorbital nerves. The anterior limit should be $1.5 \mathrm{~cm}$. from the orbital rim to avoid anterior migration of the beads and subsequent short fornix.

The extent of the dissection is related to the magnitude of enophthalmos to be corrected and should not be larger than necessary.

* Manufactured by Fisher Scientific Co. 623 Greenwich St., New York, N.Y. 
The Pyrex brand solid glass beads are then picked up with the suction tip (Fig. C) and inserted into the subperiosteal space (Fig. D).
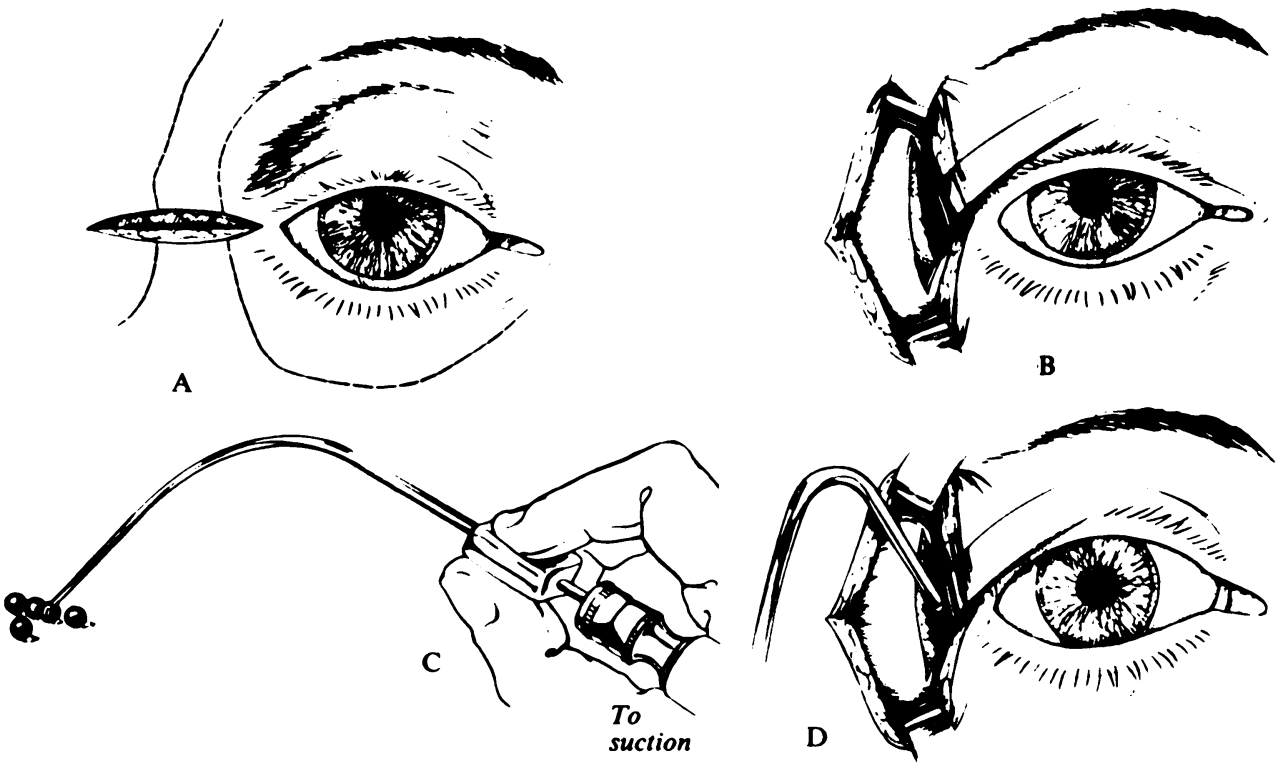

FIGS A, B, C, AND D Posterior subperiosteal glass bead imblantation (From Simith and Cherubini, 1970)

The bead-inserter devised by Guibor and Smith (1972) eliminates the time-consuming step of inserting the beads one by one, but has the disadvantage of too sudden and forceful delivery of groups of beads with consequent possible tearing of the periosteum and migration of beads. It should only be used by very experienced operators.

A medium-size conformer can be placed in the socket to cvaluate the degree of correction obtained. Additional beads may then be introduced until the desired effect is achieved.

The skin is re-approximated with nylon or silk sutures, and the beads should be spread out by inserting a finger in the anophthalmic socket, avoiding mass formation that may impinge on the levator superiorly with consequent functional deficit. This manoeuvre also aids in the later fitting of the prosthesis.

A light pressure dressing is placed on the orbital area.

In cases of medial defects the beads may be inserted through a supero-medial or infero-medial approach, by a similar technique. The trochlea, lacrimal sac, and inferior oblique muscle origin should be avoided. It is very easy to fracture the thin wall of the ethmoid, and the evaluation of the periosteum should therefore be done with maximum care.

The temporal route is to be preferred whenever possible.

Silicone beads have been used, but we prefer the Pyrex brand solid glass beads because they are inert, inexpensive, and easily obtainable, and have the advantage of being slightly radio-opaque, which aids in following the position postoperatively if migration is suspected.

\section{Present series of cases}

In our series of 55 cases the majority of patients had suffered orbital trauma (Table I, overleaf) most of them in automobile accidents. 
Table I Diagnosis in 55 cases

\begin{tabular}{lc}
\hline Diagnosis & No. of cases \\
\cline { 3 - 3 } Trauma & 32 \\
Intraocular tumour & 7 \\
Phthisis bulbi & 6 \\
Degenerated painful eye & 4 \\
Congenital microphthalmos (anophthalmos) & \\
Information not available & 5 \\
\hline Total & 55 \\
\hline
\end{tabular}

INDICATIONS

These included anophthalmic enophthalmos, enophthalmos after evisceration, extrusion of an intra-Tenon's implant when the hiatus left by the ball implant was made up of weak tissues inadequate to hold another implant, and when orbital floor implants were insufficient to correct the enophthalmos. Two cases which had a non-functioning eye were treated by this technique, but we do not recommend the insertion of glass beads into an orbit containing a viable eye, because of the possible intraocular complications.

The average number of beads implanted in adults with anophthalmic enophthalmos was 47 (Table II) and in children 33. In two cases in which the globe was present, 28 beads were inserted.

Table II Average number of glass beads implanted into the posterior orbit in 44 cases

\begin{tabular}{|c|c|c|}
\hline Diagnosis & No. of cases & No. of beads each \\
\hline $\begin{array}{l}\text { Anophthalmic enophthalmos } \\
\text { With extruded ball implant }\end{array}$ & 8 & \\
\hline With ball implant or eviscerated globe & 34 & 46 \\
\hline Enophthalmos with the globe in place* & 2 & 28 \\
\hline Total & 44 & \\
\hline
\end{tabular}

*Best corrected vision perception of light

COMPLications (Table III)

(I) Overcorrection, by the insertion of too many beads, will produce a reduced socket and may be the cause of local hyperaesthesia and pain. Removal of the excess beads corrects both situations.

Table III Complications

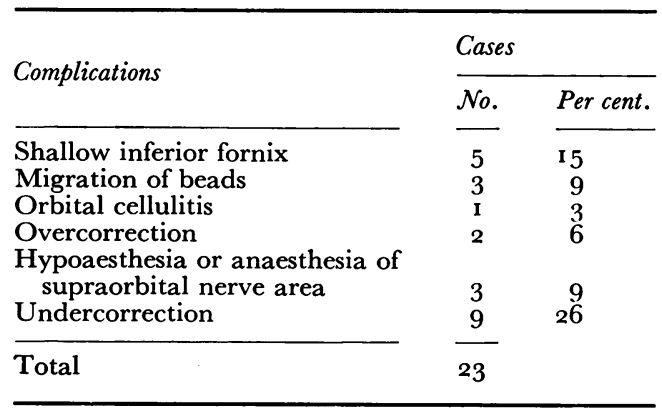


(2) Hypoaesthesia or anaesthesia in the area of distribution of the supraorbital or infraorbital nerves may be distressing to the patient. This is probably related to extensive medial dissection in the area of these nerves. The hypoaesthesia usually disappears after several months to one year, but is occasionally permanent.

(3) Migration of beads through perforations in the periosteum. In our experience there were only three cases in which one or two beads came to rest under the conjunctiva and were removed through small incisions. It is conceivable that beads may migrate into the maxillary sinus through an orbital floor fracture, but this has not occurred in our cases. Any such fracture should be covered with a sheet of alloplastic material as a primary procedure.

(4) Ptosis may result whenever the conglomeration of beads is deposited subperiosteally on top of the levator muscle. Spreading out the beads to form one single wide sheet will prevent this complication. When it occurs re-operation should be performed and the beads replaced in the recommended position.

(5) A shallow inferior fornix may result from elevating the periosteum of the orbital floor too far anteriorly. A modified prosthesis or removal of the beads is necessary to correct the deformity.

(6) Orbital cellulitis may be caused by contamination during surgery and usually is controllable with systemic antibiotics.

(7) Retinal folds and retinal oedema have been observed in a few cases of enophthalmos with a non-functional eye, when glass beads were implanted into the posterior orbit. This could be due to pressure on the globe by the beads. Because of this possibility the operation is contraindicated in the presence of a functioning eye.

(8) Postoperative transient pain and oedema in the socket may occur, but usually subside in a few days and require no special management if not persistent.

(9) Undercorrection is considered to be a complication, but it is easily corrected with a second similar procedure. All such cases in our series were successfully corrected by a second, and in one case a third, glass bead implant.

We have encountered no case of intolerance to the Pyrex brand solid glass beads since the procedure was first used in 1964 .

\section{Results}

In all the cases treated by subperiosteal posterior orbital bead implantation there was an obvious cosmetic improvement, with functional correction of both the enophthalmos and the deep supratarsal sulcus (Figs $\mathrm{E}$ and F, overleaf).

Mr. H. P. Gougelmant $\uparrow$, an experienced optician, who fitted the majority of these patients postoperatively with moulded prostheses, states that this procedure has greatly improved the ease of fitting and has reduced the necessary size of the prosthesis.

\section{Summary}

55 cases of posterior subperiosteal glass bead implantation are presented. The technique and complications are described. This operation is our procedure of choice in anophthalmic enophthalmos with a supratarsal sulcus deformity and has become a standard procedure in the Oculo-Plastic and Reconstructive Department of the Manhattan Eye, Ear and 


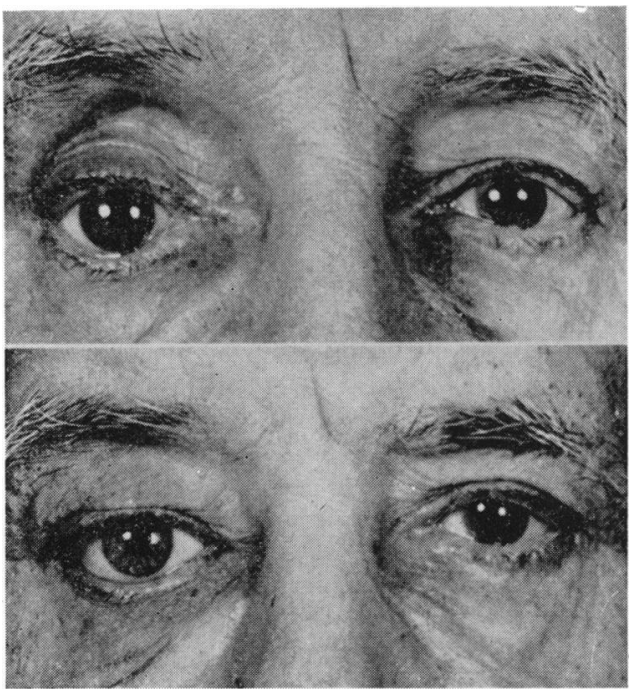

FIGS E AND F Preoperative and postoperative appearance (From Smith and Cherubini, 1970)

Throat Hospital. The operation has proved its usefulness in approximately roo cases operated on in the last 7 years. The procedure is simple and relatively free of complications if performed according to the technique described.

We wish to thank Mir. H. P. Gougelman for his assistance, and Dr. T. D. Cherubini and C. V. Mosby, Ltd for allowing us to reproduce the illustrations.

\section{References}

Bartlett, R. E. (I966) Amer. F. Ophthal., 61, 68

Callahan, A. (1966) "Reconstructive Surgery of the Eyelids and Ocular Adnexa", p. 228. Aesculapius, Birmingham, Ala. Gutler, n. L. (1946) Amer. F. Ophthal., 29, 176 DEVOE, A. G. (1945) Ibid., 28, I 346 GUiBor, P., and smith, B. (1972) Trans. Amer. Acad. Ophthal. Otolaryng., 76, 529 HILl, J. c., and RADFORD, c. J. (1965) Amer. F. Ophthal., 6o, 487 HUGHES, W. L. (1955) Ibid., 40, I I 2 SHERMAN, A. E. (1952) Ibid., 35, 89 SMITH, B., and CherUbinI, T. D. (1970) "Oculoplastic Surgery". Mosby, St. Louis - LEONE, C. R., and BEYER, C. K. (197I) "The use of glass beads as primary and secondary implants" in "Proc. XXI Int. Congr. Ophthal., Mexico, 1970", pt 2, p. 1474. Int. Congr. Ser.

No. 222. Excerpta Medica, Amsterdam - OBEAR, M., and LeONE, C. R. (1967) Amer. F. Ophthal., 64, 1088 SPAETH, P. G. (1970) Int. Ophthal. Clin., 10, 791 STONE, w., JR. (1965) "Complications of evisceration and enucleation" in "Complications in Eye

Surgery", ed. R. M. Fasanella, p. 388 . Saunders, Philadelphia vannas, s. (1958) Acta ophthal. (Kbh.), 36, 444 